\title{
CONSUMO, CIUDAD Y GLOBALIZACIÓN
}

\author{
POR \\ MERCEDES ARRANZ LOZANO \\ JOAQUÍN BOSQUE MAUREL
}

La Humanidad tiene que atender inexcusablemente unas necesidades muy concretas de bienes y servicios. Por exigencia biológica, pero también por la necesaria atención de ciertos anhelos y precisiones menos materiales. $\mathrm{Y}$, asimismo, como parte de los mecanismos que hacen posible las actividades económicas. En ese papel vario de la oferta y la demanda, del consumo en definitiva, la ciudad ha tenido y tiene singular importancia. Un papel que, desde su máxima diversidad, implícita en el origen y la evolución del hombre, tiende a contribuir a la imposición de un estadomundo, de una globalización uniforminadora, que se enfrenta a limitaciones regionales y locales.

\section{El consumo, base del desarrollo de la Humanidad}

Las necesidades implícitas en su subsistencia y perduración biológicas pero también en sus exigencias racionales constituyen la base del consumo tanto individual como colectivo de la Humanidad y, por tanto, de la demanda que la sociedad humana ha planteado desde su inicio sobre la Tierra. Pero también, según «La Riqueza de las Naciones», «el consumo es el propósito y el único fin de toda producción; y el interés del productor debería ser atendido únicamente en cuanto pueda ser conveniente para los intereses del consumidor» (A. Smith, 1776. Citado por Cuadrado Roura, 1994).

Estudios Geográficos

Tomo LXI, 2000, n. ${ }^{\circ} 238$, enero-marzo 
No obstante, esas necesidades humanas son muy diversas y cambiantes, lo han sido en el pasado, lo son en el presente y quizás vean aumentar su complejidad en el futuro. Algunas de ellas, las llamadas de primera necesidad, están estrictamente ligadas a las más simples exigencias de la realidad biológica del hombre. Pero, existen otras, y desde muy antiguo, menos perentorias aunque siempre precisas para el desenvolvimiento cotidiano de la vida humana tanto individual como social.

Y en cuya satisfacción son tales los contrastes que millones de seres humanos no pueden cubrir sus más mínimas necesidades alimentarias y llegan a padecer hambre física, mientras que algunos otros dilapidan aquellos productos de los que carecen los más menesterosos, dando lugar así a lo que se ha llamado «el escándalo y la vergüenza de la pobreza y el subdesarrollo» (Schneider, 1995).

En un primer momento, la dependencia a que se encontraba sometido el hombre respecto al muy diverso escenario físico en el que su vida se desarrollaba implicó un importante abanico de demandas y ofertas. En el ámbito de la alimentación su relación con las posibilidades agrícolas, tan ligadas al medio físico, favoreció una considerable y amplia variedad de dietas alimentarias. Como señala Sorre (1944), éstas podrían resumirse en cuatro fundamentales: la del trigo, nacida en torno al Mediterráneo, la del arroz, dominante en el Asia Monzónica, la del maíz, propia del continente americano, y la del mijo, muy generalizada en el complejo mundo intertropical africano.

En cada uno de estos casos, existían - existen-productos complementarios aunque imprescindibles dadas las exigencias de una alimentación completa y sana. Así, en la dieta mediterránea el pan obtenido con harinas de cereales de invierno, se acompaña con la grasa vegetal derivada del olivo, las leguminosas que acompañan el cultivo cereal, las diversas frutas propias de la agricultura mediterránea - uvas, higos, almendras, amén de las proteínas ofrecidas por el ganado propio de cada región y la pesca marítima o fluvial. Similar complejidad por su variedad aunque muy distintos por su diferentes medios naturales y culturales caracteriza a cada una de las restantes dietas posibles.

Pero, desde muy temprano, se produjo un intercambio y difusión de determinados artículos alimenticios entre ámbitos dietéticos a veces muy distantes. Es el caso de la patata que, desde los Andes, se ha extendido no sólo a toda América sino también a Europa y a importantes porciones de Asia y Africa. Similar ha sido el comportamiento del arroz 
- como de otros frutos monzónicos--, hoy importante en la cocina mediterránea tanto como en la alimentación de los países iberoamericanos. De igual manera, el trigo ha traspasado los océanos desde Europa hasta Norteamérica, los Países del Plata y Australasia, y, a la inversa, el maíz americano se ha implantado y generalizado en el Viejo Mundo.

Una capacidad de intercambio y difusión que reside en la misma autenticidad humana, tan ligada a la razón y al sentimiento. El ejemplo más significativo lo podemos encontrar en las pautas y comportamientos implícitos en las creencias y planteamientos ideológicos y, sobre todo, religiosos específicos del Hombre. El binomio cristianismo-islamismo ha sido fundamental en la difusión/limitación del cultivo de la vid y del consumo de bebidas alcohólicas, de la demanda / consumo de ciertos ganados animales y sus productos y, en especial, del cerdo. Asimismo, ciertas pautas de la religión cristiana han sido responsables del desarrollo de la pesca en general y de la importancia, por ejemplo, del consumo del bacalao - un pez propio del Atlántico Norte - y de su singular presencia todavía hoy en la dieta de los países ibéricos, donde el consumo de pescado es especialmente relevante y popular (Deffontaines, 1948).

Parecida situación de dependencia y libertad se produce en la demanda/oferta de todo aquello necesario para la protección de la Humanidad respecto a la intemperie, muy varia según los distintos escenarios naturales. Esencial es la vivienda humana, básica para el desarrollo de la Humanidad, así como las imprescindibles prendas de vestir que han salvaguardado al Hombre desde su aparición en la Tierra. «La huella más visible de la presencia del hombre sobre la superficie terrestre es la casa»...(Pero, si) «el hombre se nos presenta como una especie ligada a su vivienda, es también el ser vivo que tiene más necesidad de ella...; (al hombre) le es preciso abrigar su cuerpo, lo que plantea a la vez el problema de la vivienda y el del vestido, del que es el único ser vivo que lo reclama» (Deffontaines, 1972).

En principio, la dependencia del medio físico fue clave en la creación de la vivienda y favorece su diversidad: albergue vegetal, vivienda troglodita, casa de madera, de piedra, de barro seco o cocido. Y, siempre, la realidad de la casa como fruto muy dependiente de los medios culturales y socioeconómicos la convierte en una señal de identidad de los pueblos y en manifestación de su variedad. Todo ello en el ámbito de una creciente globalización técnico-científico arquitectural que está imponiendo fórmulas y vivencias únicas o similares contrapuestas frecuentemente a las múltiples y complejas raíces culturales de la Humanidad (Santos, 1994). 
Pero no es menos importante la demanda/consumo de recursos ligados al desenvolvimiento de la razón y el sentimiento, y por tanto exclusivos de la especie humana. Y muy dependientes de los influjos históricoculturales presentes en las vivencias derivadas de la lengua y de su expresión literaria y también de formulaciones tan ligadas a la razón y el sentimiento como la música y el canto y las artes materiales en su versión popular y colectiva y en las más minoritarias e individualizadas. Y, por tanto, sometidas a las diferentes fases de expresión por las que ha pasado el Homo sapiens: aparición de la escritura, invención de la imprenta, difusión de las telecomunicaciones y la informática.

La atención de todas estas exigencias primarias y secundarias ha provocado desde un primer momento la invención y el uso de artefactos e instrumentos muy diversos pero cada vez más necesarios en la obtención y la preparación de los alimentos, de la vivienda y de las necesidades de la razón y el sentimiento. $Y$ que tienden a convertirse en artículos de primera necesidad a causa de la costumbre y la rutina, aunque también del influjo de las actividades económicas y de su conversión en un medio imprescindible para el mantenimiento de la humanidad.

En menudo, un concreto artefacto puede llegar a ser esencial en la vida cotidiana de la Humanidad. Hoy puede hablarse de una «civilización del automóvil» capaz de imponer no sólo hábitos de consumo sino, aun más, crear modos de vida y provocar cambios tanto en las formas del habitat como en las mismas costumbres individuales y colectivas. Y que está ligada a la presencia de toda una gama de artefactos e instrumentos tanto en el hogar familiar como en la convivencia social colectiva.

Se trata, en definitiva, de un «confort» muy ligado a la «moda», es decir a la generalización de usos, modos o costumbres de escasa o dudosa duración, y de sus continuos y no siempre justificados cambios. Muy supeditadas, además, al influjo de una oferta imprecisa y artificializada y de la presión publicitaria ejercida por las empresas productoras o por los intermediarios que tienden a controlar y dominar el juego oferta/demanda.

\section{La ciudad y la evolución histórica del consumo}

El consumo es una exigencia de la especie humana y, por ello, todas las razas y sociedades que conformaron y conforman la Humanidad pro- 
tagonizan el juego oferta-demanda. Pero no cabe duda que el desarrollo socioeconómico tiene una especial importancia tanto en el volumen como en la calidad de lo consumido. En esa línea, el papel desempeñado por la ciudad ha sido - y es- fundamental en la creación y difusión de las pautas sociales y culturales y, por tanto, de los hábitos y modos de consumo.

Las primeras urbes fueron centros políticos y religiosos muy jerarquizados, pero también y, en especial, lugares de encuentro y de intercambio entre los diferentes grupos humanos y, en definitiva, centros básicos de contratación comercial una vez que los excedentes productivos se generalizaron (Davis, 1973). Desde entonces, la evolución del consumo a lo largo del tiempo nos ofrece, al menos, tres grandes momentos que coinciden con las tres principales etapas por las que, formal y funcionalmente, ha pasado la ciudad y que dieron lugar a determinadas maneras de relación social e intercambio mercantil.

Tras una larga etapa previa de una humanidad nómada, recolectora y autosuficiente, la primera revolución económica, neolítica y urbana, habida en torno al quinto/sexto milenio antes de Jesucristo y creadora de las denominadas paleourbes (Mumford, 1961) o ciudades preindustriales (Sjoberg, 1960), implicó a lo largo de varios milenios un consumo muy limitado, que pudiera calificarse de "arcaico», dominado por una demanda sometida a la atención de las necesidades más primarias. Sólo las fuertes desigualdades sociales existentes y la presencia de unas minorías detentadoras de la riqueza y el poder permitieron el desarrollo de un consumo suntuario y selectivo que contrastaba violentamente con la pobreza dominante.

La actividad comercial, muy individualizada y limitada por el corporativismo, se concentraba en el centro urbano en una serie de calles especializadas según productos y usos. Además, existían lugares de auge semanales (mercados) y estacionales (ferias) de máxima actividad contractual que tendían a localizarse en espacios urbanos periféricos. Esta situación localista y fraccionada no impedía importantes corrientes de tráfico y un poderoso comercio internacional que concedió a la ciudad un papel excepcional de control socioeconómico y, a veces, político tanto en la Antigüedad clásica como en la Edad Media (Pirenne, 1972).

La revolución socioeconómica de los siglos XVI al XviI fue el origen de un nuevo modelo urbano, la ciudad industrial, que, favorecida por los grandes descubrimientos geográficos y la apertura de las primeras rutas 
oceánicas, provocó un extraordinario desarrollo socioeconómico y muy importantes cambios en las pautas y los comportamientos de la población. Cambios ligados a la introducción de nuevas doctrinas económicas presididas por el liberalismo y su principal expresión, el capitalismo financiero. En consecuencia, a lo largo de los siglos XIX y xx, se produjo un tremendo incremento de las necesidades y del consumo, así como la difusión generalizada a casi todas las clases sociales de la demanda de todos los bienes y servicios posibles y no sólo de los de primera necesidad.

Se ha llegado así, desde comienzos del siglo xx, a una cultura/sociedad del «bienestar» y a un consumo de «masas» que extendió la exigencia y la necesidad no sólo de lo primario sino más aún de lo antes considerado como secundario - sanidad, enseñanza, ocio- a todo el colectivo social. La atención de las exigencias de esta nueva manera de entender la vida introdujo importantes cambios en los modos mercantiles y, más aun, en su gestión.

Al lado de la difusión de la sociedad anónima como principal forma de empresa y el nacimiento de las corporaciones transnacionales, hay que destacar la normalización formal y cualitativa, casi siempre por la acción administrativa, de los artículos de consumo y de los lugares de venta, la creación de espacios cerrados y cubiertos (mercados municipales o de barrio) para localizar el pequeño comercio individualizado, la aparición de las grandes superficies de venta privadas (grandes almacenes de oferta múltiple), la generalización del precio preestablecido, fijo y único y la mayor diferenciación entre mayoristas y minoristas. Todo ello sin que desapareciesen en ningún caso las modalidades mercantiles tradicionales: tiendas diversas y especializadas, mercados callejeros, venta ambulante, etc.

La cultura del bienestar preludió y permitió, en una tercera etapa, hoy en pleno desarrollo, la aparición de la ciudad postindustrial, propia también del postmodernismo, caracterizada por la generalización de la tecnociencia y la información y dominada por una red de flujos - materiales e informáticos- que se sobreponen, incluso anulándolos, al espacio y a los lugares. «Lo que emerge de este proceso de reestructuración... no es la profecía orwelliana de un universo totalitario controlado por el Gran Hermano sobre la base de las tecnologías informáticas. Es mucho más sutil, y asimismo potencialmente más destructivo, en forma de desintegración y reintegración social. No hay una opresión tangible, ni un enemigo identificable, ni un centro de poder que puede hacerse responsable 
de determinadas presiones sociales... El hecho fundamental es que el sentido social desaparece de los lugares e incluso de la sociedad y se diluye y difumina en la reconstrucción lógica del espacio de flujos cuyo perfil, origen y propósito último son desconocidos aun por muchos de los entes integrados en la red de cambios» (Castells, 1989).

Uno de sus frutos es la cultura hoy dominante del «consumismo" y el «despilfarro», junto al contraste entre la «globalización» económica y las tensiones regionalistas, el «individualismo» y la «insolidaridad» (Santos, 1996). Un contexto que puede enmarcarse en el tránsito al «postmodernismo", en el paso de las verdades establecidas e indiscutibles al rechazo de lo razonable y lo teórico, de la consideración del interés general al mayor peso de las necesidades personales e individuales.

Notas que no excluyen las ventajas del crecimiento económico y de las relaciones y los contactos a nivel mundial, ni tampoco la presencia, no siempre minoritaria, del «ciudadano» solidario y universal. La preocupación por el medio ambiente es un hecho común, lo mismo que la proliferación de agrupaciones humanas que se plantean la defensa de las minorías, la ayuda a los pueblos menos favorecidos y la difusión de los principios de justicia social y solidaridad humana. «Durante todo este tiempo, la sociedad ha cambiado: ya no es una pirámide con unos pocos arriba y muchos abajo, sino que se ha convertido en una especie de vieja peonza, más ancha por en medio. El problema ya no es el que plantearon los fabianos hace cien años: ¿Por qué hay muchos pobres?, sino más bien: ¿Por qué sigue habiendo unos pocos pobres?... Ni el urbanismo ni el estado del bienestar del siglo xx han conseguido que desaparezcan (los pobres) y tampoco ofrecen una explicación satisfactoria de su existencia: unos dicen que es culpa del sistema y otros del pecado original» (Hall, 1988).

Hay que añadir la confirmación y mejora de los modos de oferta y venta introducidos en la etapa anterior y que han perjudicado notoriamente al comercio tradicional. El deterioro físico y la decadencia demográfica de los cascos antiguos ha afectado decisivamente, a veces hasta su desaparición, al pequeño comerciante allí asentado. Pero, además, la ordenación funcional de la ciudad industrial y postindustrial y el consiguiente traslado de las áreas residenciales a la periferia urbana ha favorecido a las grandes superficies comerciales, y al creciente peso del capital internacional. Es cierto que las modalidades tradicionales no han desaparecido y que, en algunos casos - venta ambulante, merca- 
dos callejeros - se han desarrollado y actualizado, pero también lo es la aparición de nuevas formas mercantiles, como la venta a distancia, por catálogo, y a través de las telecomunicaciones, correo, teléfono, informática (Checa, 1991).

\section{El consumo en la actualidad: su diversidad espacial}

En el mundo actual, el consumo sigue ofreciendo una imagen diversa, compleja y difícil de valorar y diferenciar espacial y socialmente. Primero, por su compleja y matizada estructura derivada de sus múltiples exigencias materiales y espirituales tanto individuales como colectivas. Pero también por la dificultad de contar con un medio de análisis y conteo válido para cada una de las distintas formas con que se presentan los bienes y servicios a consumir, como por las diferentes etapas en que se encuentran las varias sociedades que componen la Humanidad en el momento actual.

No obstante, y teniendo en cuenta al conjunto de la sociedad mundial, se ha recurrido con frecuencia al Producto Nacional Bruto como un medio de comparar y enfrentar los diversos modelos de consumo existentes. Como es sabido, la renta nacional o producto interior bruto (PIB/PNB) de un país consiste, básicamente, en la suma del consumo privado, la inversión privada, el gasto público y el saldo exterior neto (Cuadrado Roura, 1994). Y si el consumo es la parte proporcional más importante de dicha suma, el valor global de la renta, sobre todo a nivel personal, puede constituir un índice muy significativo de las varias posibilidades de consumo existentes en cada uno de los estados que hoy existen en la Tierra.

Nada más expresivo, en este sentido, que la enorme distancia que separa a las diversas naciones en cuanto a su PNB/PIB estimado. En 1997, según el Anuario El País, existía una enorme diferencia entre las 45.330 \$ que detentan los habitantes de Luxemburgo, país con la renta más elevada del mundo, y los $90 \$$ con que cuentan los habitantes de Mozambique, último estado en la lista de 210 . Entre estos extremos existe grandes diferencias tanto dentro de un mismo continente como tanto entre sus distintos componentes. Y tampoco cabe olvidar los contrastes sociales y espaciales propios de cada estado.

A modo de estereotipo se acostumbra a pensar en «países desarrollados» que comprenden algunos subcontinentes como los Estados Uni- 
dos, Canadá, o la Unión Europea, o países muy concretos, como Japón. $Y$ en contrapartida, existen los «países en desarrollo» que dominan América Latina, Asia y África. Aunque no faltan unos espacios intermedios no menos significativos. Así cabe establecer tres grandes franjas; la primera la constituida por los estados que reciben entre $46.000 \mathrm{y}$ 10.000 dólares «per cápita»; la segunda, integrada por las unidades nacionales que oscilarían entre 9.999 y $1.000 \$$ por habitante, correspondiendo la tercera y última a aquellos países con niveles inferiores a 1.000 dólares «per cápita».

El grupo de estados incluidos en la franja de máxima renta disponible son un total de cincuenta y representan el $24 \%$ de la lista. De esos cincuenta, la mitad detentan rentas elevadas, superiores a 20.000 dólares por habitante, y de la que forman parte los países económicamente más desarrollados del Centro y Norte de Europa - Luxemburgo, Suiza, Austria, Bélgica, Alemania, Francia, Inglaterra, Italia, Holanda, etc.-, a los que se añaden otros países aislados y dispersos por América- Estados Unidos--, Asia -Japón, Hong Kong, Kuwait y Brunei- y Oceanía (Australia).

En la misma franja, pero con valores inferiores a 20.000 aunque superiores a 10.000, aparecen otros veinticinco estados entre los que se destacan, además de Canadá, el mediodía y oeste de la Europa comunitaria -España, Grecia, Portugal, Irlanda-, Groenlandia y las Islas Vírgenes, más algunos países asiáticos - Israel, Emiratos Arabes y Corea del Sury otros ubicados en América Central -Bahamas, Martinica, Antillas holandesas-, aparte la Polinesia francesa. En un análisis de este conjunto, llama la atención dos hechos; la existencia de países muy distantes y distintos espacialmente aunque semejantes por su nivel de renta, y la rapidez con que en algunos países se ha incrementado en poco tiempo su renta: Emiratos Arabes, Corea del Sur, Hong Kong.

En el polo opuesto del ranking mundial se encuentran los países con menos de $1.000 \$$ por habitante, que suman un total de 73 y conforman el 35\% de toda la lista mundial. En ellos cabe señalar el grupo que recibe cifras entre 1.000 y 500 dólares: 26 estados, el 13\% mundial. Algunos son europeos -Albania, Yugoeslavia y Moldavia-, otros se ubican en Asia Central - Armenia, Georgia, Turkmenistán, Azerbaiyan-, en el Extremo Oriente - Corea del Norte, China-, en Iberoamérica -Bolivia, Cuba, Honduras - y en Africa, Guinea, Jibuti, Senegal. Por su parte, entre los que no alcanzan los 500 dólares y superan los 180 , se en- 
cuentran 25 estados, en su mayoría africanos - Angola, Benín, Ghana, Gambia, Kenia, Mali, Togo, Sudán, Uganda-, asiáticos —Pakistán, Mongolia, India, Yemen-y un europeo, Estonia. Por último se destacan cinco - Burundi, Somalia, República del Congo, Etiopía y Mozambique, todos africanos, los más pobres de la Tierra y que oscilan entre 180 y 90 dólares, la mínima renta correspondiente a Mozambique.

Entre las dos franjas señaladas, máxima y mínima, se encuentran la mayoría de los países, en total 87 , que representan el $41 \%$, y que reciben cifras de renta entre 10.000 y 1.000 dólares «per cápita». Un subgrupo que oscila entre 10.000 y 5.000 \$, está constituido por tres países europeos -Eslovenia, Malta y Chequia-, otros iberoamericanos, Argentina, Chile, Uruguay, Barbados, Antigua y Barbuda, y varios asiáticos, Arabia Saudita, Libia y Seychelles. Por debajo de 5.000 y rebasando los 1.000 aparecen numerosos países iberoamericanos como Brasil, Venezuela, México, Paraguay, Panamá, Costa Rica, aparte varias islas del Caribe, y otros asiáticos, Oman, Líbano, Turquía y Tailandia, y africanos, Argelia, Marruecos, Túnez.

Esta evidente desigualdad en la capacidad de consumo se hace aún mayor si se tienen en cuenta las rentas interiores de cada país. Con la particularidad de que, en general, la distancia se incrementa al disminuir las rentas nacionales como es visible en los estados menos desarrollados, por ejemplo, de Africa e Iberoamérica. En Brasil, en 1989, el $11 \%$ de su población disponía del $70,5 \%$ de la renta, mientras que el $60 \%$ de ese misma población sólo contaba con el 11\% (Sánches Ross, 1996). Una estructura generalizada en los países en desarrollo; según el Banco Mundial (1990), en estas naciones, un total de 1.110.000 personas consideradas bajo el nivel de la pobreza, alrededor del $20 \%$ de la población total, sólo contaban con unos ingresos medios inferiores a 100 dólares «per cápita», apenas el $1 \%$ de la renta percibida (Romero y otros, 1992). En cambio, una minoría que, en conjunto, apenas rebasa el 2-3\% de cada país tiende a beneficiarse de valores que nunca descienden del $50 \%$ y, a veces, se acercan a los dos tercios de la renta total.

Muy distinta es la situación en los países desarrollados. En los Estados Unidos, y con un número significativo de pobres de solemnidad (homeless), alrededor del 6\%, la amplitud no es tan acusada: el $10 \%$ de sus habitantes controlan en torno al $31 \%$ de la riqueza nacional, constituyendo las clases medias (60\%) la mayoría de su sociedad, con cerca del $50 \%$ de 
la renta. Y la situación no es muy distinta en el resto de los países desarrollados: el $28 \%$ de la renta de Canadá, el $33 \%$ de Francia y el $28 \%$ de Suecia es absorbido por el 10\% de las poblaciones respectivas (Romero y Pérez Esparcia, 1992). En España, finalmente, la estructura social en relación a la renta es la siguiente según los últimos análisis: las clases altas y medio-altas significan en torno al 18\%, las clases medias el $57 \%$ y las bajas, al menos, el 25\% (Díez Nicolás, 1992).

Es indudable que el volumen de la renta tiene mucho que ver con la cuantía del consumo y, más aún, con la capacidad de elección y selección que tiene el consumidor. En la segunda mitad del pasado siglo, el estadístico y economista Christian L. E. Engel afirmaba: «Cuanto más pobre es un individuo, una familia o un pueblo, mayor ha de ser el porcentaje de su renta necesario para el mantenimiento de su subsistencia física, y a su vez mayor será el porcentaje que debe dedicarse a la alimentación» (cit. Cuadrado Roura, 1994).

La validez actual de esta «ley» de Engel es absoluta y la realidad del mundo en que vivimos la corrobora plenamente. En 1900, en los Estados Unidos, el gasto medio familiar en alimentación representaba el $47 \%$ de los ingresos medios de un norteamericano; en 1950, había descendido al $32 \%$ y, en 1990 , no llegaba al $20 \%$. Como contrapartida, la demanda relativa a la vivienda y su equipamiento había pasado del $25 \%$ en 1960 al 36\% en 1990, mientras que el consumo relacionado con el vestido apenas había variado. Y en todos los casos, la variedad y la calidad de la oferta - y por tanto de las posibilidades de consumo- han aumentado muchos puntos en los últimos decenios (Cuadrado Roura, 1994).

Pero la evolución del consumo tiene en cuenta muchos más factores que el simple incremento de la renta. Un hecho fundamental en las últimas décadas ha sido el cambio de los modos de vida, tanto familiares como colectivos, especialmente en las ciudades. $Y$, sobre todo, la cada vez mayor participación de la mujer en las actividades profesionales y públicas, así como el abandono de los viejos cascos urbanos por la residencia periférica. El automóvil se ha convertido en un artículo de consumo y uso generalizado con la única diferencia de calidad y precio según la distinta capacidad económica de las familias. $\mathrm{Y}$, en esta «civilización del automóvil», la demanda alimenticia, sin disminuir en volumen, parece dirigirse hacia los platos preparados congelados - multiplicada casi tres veces y media en Gran Bretaña entre 1983 y 1988 y en torno a dos veces en Fran- 
cia y Alemania en los mismos años -, a la vez que el gasto en alimentación fuera del hogar está creciendo espectacularmente en función de los nuevos tipos de vida y del cambio de horarios que se está produciendo en las grandes áreas metropolitanas.

A todo ello cabe añadir como aspectos muy influyentes en el consumo, la evolución de la estructura demográfica y sobre todo el envejecimiento de la población en los países más opulentos y el crecimiento de los grupos juveniles en los menos desarrollados, el aumento del tiempo libre y de las posibilidades de ocio, y, finalmente, el creciente nivel cultural de los ciudadanos, su mayor y mejor información y la consiguiente postura crítica - es relevante el papel de la publicidad - que tiende a extenderse entre todos los colectivos.

Cuatro notas principales señala Cuadrado Roura (1992) en las pautas de conducta de los consumidores en la actualidad, sobre todo en la Unión Europea: a) el individualismo que prioriza todo cuanto permite la comodidad, el placer y una mejora de la propia existencia; b) la revalorización de la seguridad; por ejemplo, de las condiciones sanitarias de los alimentos, los vehículos y la vivienda; c) el papel simbólico de ciertos artículos que proyectan una determinada imagen respecto a los demás, y d) un mayor deseo de cambio y novedad frente a la estabilidad que antes predominaba en el vestuario, los viajes, las vacaciones y las vivencias y contactos.

En todo lo anterior, y sin olvido de su diferente nivel de ingresos, cabe insistir en la libre capacidad de decisión del consumidor tanto individual como colectivamente. Sin embargo, la política económica, financiera y social de los estados ha tenido, al menos desde la implantación de la «cultura del bienestar", una gran influencia en las pautas del consumo. En especial, en todo aquello que favoreciera - incluso impusiera-el ahorro global e individual como parte principal de la inversión y la acumulación de capital, factores decisivos o, al menos, influyentes en el desarrollo socioeconómico. Aun en el momento actual en que se discute y critica ese «estado del bienestar», el neoliberalismo emergente y sus doctrinas no dejan de intervenir - y dirigir - en las actividades más cotidianas, como el consumo, y aun más en las diferentes posibilidades de la economía de cada nación. El conjunto de directrices de la Unión Europea que tiene como objetivo el establecimiento de una «moneda única» $\mathrm{y}$, en último término, la consecución de la unidad política europea es aleccionador y significativo. 
El consumo en España

Un ejemplo de la complejidad que, en la actualidad, tiene el consumo puede encontrarse en el análisis de su evolución y sus caracteres en España. Un análisis que debe insertarse en el devenir sociopolítico del siglo xx español y no menos en el proceso histórico por el que ha atravesado últimamente el país. Un proceso que se integra en cierta medida en el sufrido por el conjunto de los países del Primer Mundo desde la Primera Revolución Industrial.

En este sentido, cabe señalar cómo la evolución de los distintas formas de consumo desde una que podría calificarse de «arcaica» hasta otra considerada de «consumo de masas», ha sido una constante en todos los países industrializados, al menos desde finales del siglo xix. Concretamente fue Estados Unidos el primer estado en dónde se puso de manifiesto esta última fase del consumo.

Un proceso que también tuvo lugar en España aunque con un cierto retraso, unos treinta años más tarde y con unas características diferentes y consustanciales al devenir de los últimos cien años de la Historia española. A este respecto no se puede olvidar cómo hasta mediados del siglo xx más de la mitad de la población activa española estuvo integrada en el sector primario. Sólo a partir de 1950 descienden estas actividades por debajo de ese porcentaje, en tanto que, progresivamente, se acrecentaban los sectores secundario y terciario, mayoritarios en conjunto desde entonces (Puyol y García Ballesteros, 1989).

En relación al consumo, en España se pueden distinguir a lo largo del siglo $\mathrm{xx}$, al menos dos fases distintas. Una primera, «arcaica» que estuvo vigente hasta la década de los cincuenta, y otra de «consumo de masas» que, iniciando su apogeo durante la década de los sesenta, tiene sus raíces en el decenio anterior.

El modelo arcaico se manifestó en una sociedad eminentemente rural, en la que más del $50 \%$ de la población activa trabajaba en el sector primario y más del $55 \%$ habitaba en núcleos rurales de menos de 10.000 habitantes. Una sociedad en la que no existían unas clases medias urbanas y, al contrario, aparecían dos grupos sociales bien diferenciados; uno, minoritario y de gran poder adquisitivo, constituido por personas integradas en la aristocracia y la burguesía terrateniente, las «viejas clases patrimoniales» según A.Ortí (1987); en el extremo contrario se distinguía una clase social mayoritaria pero de baja capacidad económica y muy limitado poder adquisitivo. 
Este complejo social dual y segregado se desenvolvía en un contexto económico cuyo escaso excedente productivo no se orientaba hacia el consumo, sino hacia una acumulación primitiva de capital que atendía a distintas formas de ahorro popular y diferentes maneras de captación de recursos. Y que desarrollaba un tipo de consumo restringido y de élite originado por la minoría más rica del país (Alonso y Conde, 1994).

En esta sociedad van surgiendo, aproximadamente desde 1920, otros grupos sociales con capacidad económica elevada pero no pertenecientes a las antiguas clases patrimoniales, sino a nuevos sectores sociales urbanos: profesionales, comerciantes, industriales, ejecutivos. Estas nuevas clases medias fueron enseguida, a partir de los años treinta, cuantitativamente mayores que las tradicionales, y se desarrollaron, sobre todo desde el final de la Guerra Civil, al calor de una incipiente industrialización que, como en Norteamérica, se orientó hacia productos como el automóvil o los electrodomésticos (Bosque Maurel y Méndez, 1995).

Asimismo, estas nuevas clases sociales, a diferencia de las antiguas y como en otros países europeos, se asociaron al consumo en masa como una manera de identificarse con valores simbólicos más modernos, al propio tiempo que se distanciaban de la antigua y rancia tradición española. Empero, la Guerra Civil española constituyó un corte en lo que pudo haber sido un proceso evolutivo de «modernización» de la sociedad y del modelo de consumo. Al mismo tiempo que se produjo un cierta pérdida en la renta «per cápita» —los índices de 1935 no se recuperaran hasta 1955-, se volvió a la primacía de ciertos valores simbólicos asociados al antiguo régimen español: el sentido del honor, el predominio de la tradición y a un cierto rechazo de la producción en serie (Alonso y Conde, 1994).

En el lado opuesto se situaban las clase sociales económicamente más desfavorecidas. Estas, a lo largo de la postguerra, que en España perdurará económicamente hasta 1959 en que se aprueba el Plan de Estabilización, padecieron la represión del poder político y una regresión en el ámbito de la alimentación y la salud. Se originó así un tipo de subconsumo que no permitía cubrir las más elementales necesidades, y en el que el racionamiento y el mercado negro (estraperlo) afectaban a todo el conjunto de productos y bienes de uso básicos en la vida cotidiana.

Así, durante los años de posguerra y hasta los primeros años sesenta, el modelo de sociedad fue bastante semejante al que había existido desde comienzos de siglo, aunque ya se estaban produciendo cambios im- 
portantes. Desde 1950 se apreció una rápida evolución hacia mayores proporciones de población urbana y de los sectores secundario y terciario, que favoreció la aparición de un importante proletariado fabril y urbano. En paralelo, con la introducción de algunos hábitos propios del «estado del bienestar» como el seguro de enfermedad y los subsidios familiares, el modelo de consumo empieza su transición hacia una oferta creciente y una demanda más diversa y masiva (Bosque Maurel y Méndez, 1995).

Aunque la aceleración del modelo de consumo de masas en España tuvo lugar en las décadas de los sesenta y setenta, es evidente también que 1955 marca la transición entre el viejo modelo autárquico y el futuro modelo tecnocrático y desarrollista de los años sesenta y el cambio en las pautas consumistas. En ese año se aprecia la entrada muy tímida de las multinacionales, sobre todo americanas - Coca Cola, Winston, entre otras-y, asimismo, la aparición minoritaria de productos y marcas extranjeras. A ello se añade una cierta ampliación de los niveles de consumo de la población española, aunque ésta sigue adoleciendo de elevados grados de pobreza socio-cultural y de falta de libertad y represión política (Alonso y Conde, 1994).

Pero el desencadenante básico fue el Plan de Estabilización Económica de 1959 debido a la entrada en el gobierno español de un grupo de tecnócratas afines a los principios europeistas del Tratado de Roma, y a sus consecuencias inmediatas, los Planes de Desarrollo Económico iniciados en 1964 apenas afectados por la creciente inquietud política y los problemas derivados de la evolución económica mundial - crisis sucesivas del petróleo de los años setenta—a los que España estaba cada vez más ligada (García Delgado, 1990).

El proceso de industrialización desencadenado entonces provocó elevados niveles de población urbana en un proceso muy rápido de veinte años (1950-1970) a partir de un modelo de crecimiento que incrementó los desequilibrios regionales, y originó a su vez una sociedad con altos porcentajes de las actividades no agrarios claramente superiores desde 1970 (García Ballesteros, A. y Pozo Rivera, E., 1994). La expansión de las industria en serie del automóvil, naval, maquinaria pesada, electrodomésticos y electrónica originará las principales mercancías del consumo masivo de las nuevas clases obreras urbanas.

Tres son los principales tres rasgos definitorios del «consumismo» consiguiente (Alonso y Conde, 1994): a) el consumo se convierte en una salida con una fuerte carga simbólico-motivacional lógica en un con- 
texto político de represión y falta de libertades, y en momentos en que en otros países industrializados surgían movimientos sociales críticos al «consumismo»; b) la percepción de los valores sociales asociados a las viejas clases patrimoniales va a ser utilizada por las multinacionales para definir una sociedad de consumo a la española, y c) el carácter dependiente de un consumo generado dentro de un «desarrollismo» autoritario muy vinculado a las multinacionales y a la vigente división internacional del trabajo convierte al turismo, a la emigración a la CEE y a las inversiones extrajeras en la base de ese desarrollo y del consumo resultante.

Espacialmente, el consumo de masas se centraría primero en las áreas industriales que, asentadas en especial en las grandes urbes del país, serán las primeras en adoptar sus innovaciones. Después, la ciudad será inductora de los nuevos productos y de las mismas pautas de consumo. Más tarde, las innovaciones consumistas se difundirán a todo el resto del «sistema urbano» español, y las zonas rurales actuaran de acuerdo al modelo recibido o impuesto desde el espacio urbano, configurándose un modelo generalizado de aculturación.

\section{Globalización y consumo}

Un hecho fundamental en el mundo moderno es la existencia de un medio técnico-científico informacional (Santos, 1994) capaz de crear -y difundir por toda la Tierra-un conjunto común de pautas y comportamientos que están uniformizando un buen número de las actividades humanas, sobre todo las de carácter económico. En esta línea, hay que destacar la generalización de unas telecomunicaciones que, a través de una creciente y potente información, pueden poner en casi instantánea relación a todos y cada uno de los más diversos lugares de la Tierra. Y que, cada vez más, subrayan y enfatizan la interdependencia en que se encuentran todos los lugares y pueblos que componen la Humanidad, validando, en cierta forma, la afirmación de Macluhan de la Tierra como una «aldea global».

A esta realidad actual se ha llegado lentamente, en una larga evolución que tuvo su inicio a finales del siglo xv. Entonces tuvieron lugar los primeros grandes descubrimientos llevados a cabo por navegantes españoles y portugueses. $\mathrm{Y}$ que en una acción sorprendente de apenas cincuenta años 
desvelaron los «misterios» del Atlántico y el Pacífico, sacaron de la penumbra a América y aproximaron a Europa a través del Islam los mal conocidos espacios de China y la India (Wallerstein, 1979, y Taylor, 1993).

La ampliación del espacio geográfico se completó, a partir del Renacimiento y al calor del racionalismo científico que estalló en pleno siglo XVII, con el desarrollo del conocimiento de la Naturaleza y de su utilización masiva, que permitió las sucesivas «revoluciones» técnico-científicas que han transformado la Humanidad en los últimos dos siglos. Y, sobre todo, ha provocado el nacimiento e implantación de un complejo económico que, hoy, homogeiniza a través de una red global de objetos, lugares y flujos el espacio-mundo en que vivimos (Dollfus, 1994).

En definitiva, como afirma Milton Santos, se ha llegado a «un espacio (que) es un conjunto indisociable de sistemas de objetos y de sistemas de acciones» (1966), es decir se ha llegado a un sistema-mundo o a un espacio-mundo. Sin embargo, en ese espacio y/o sistema global se contraponen y se complementan lo mundial y lo local. El primero busca imponer a todos los lugares una racionalidad única, una uniformidad generalizada y creciente tanto en las cosas como en los flujos. Pero, a su vez, lo local mantiene aún en el espacio-mundo —o lo pretende-los diversos modos de su propia racionalidad, en gran medida hecha de intuiciones y tradiciones.

Por tanto, asumiendo que la «globalización» constituye el estadio supremo de la internacionalización iniciada en el siglo xvI, es indudable que la introducción en el sistema-mundo de todos los lugares, flujos e individuos se está produciendo en muy diversos grados y de muy diferentes maneras según los casos. Y con una intervención singular del consumo y sus consecuencias.

Por una parte, son abundantes los productos -automóviles, comidabasura, televisores, ordenadores-, los usos —-telefilmes, música y bailes americanos, formas de vestir, moneda plástica - y las marcas-Cocacola, Levis, Philips, Seiko —que contribuyen a la globalización uniformadora de la Humanidad. Y en la que el peso de la anglicanización es evidente (Bosque Maurel, 1998).

Pero, también son importantes las variantes regionales y locales en lo que respecta a la alimentación - pastas italianas, hortalizas chinas, salsas francesas, arroces y pescados españoles-, a la forma de vestir - vestidos regionales o religiosos-, al ocio - folklore múltiple-o a las costumbres y comportamientos, tan diversos como personas, grupos sociales o países. 
El problema principal reside en la velocidad con que se imponen las normas globalizadoras y también en la capacidad de resistencia de lo singular y lo local. Y sobre todo en la arrolladora realidad de los cambios de mentalidad que ya están imponiendo nuevas formas de relación material y cultural entre los pueblos y los individuos y, también, renovando los modos de la oferta y la demanda, en definitiva del consumo.

Así se está dando lugar a todo un conjunto de creencias, estructuras y procesos cada vez más uniformes y extendidos a toda la Humanidad y origen de un conjunto de percepciones, pautas y comportamientos más y más generalizados y en las que el dominio de la necesidad y, en cierta medida, el ansia de consumir se está imponiendo. El «consumismo», es decir «el consumo por el consumo», parece estar convirtiéndose en un hecho decisivo en la vida cotidiana y en un factor fundamental en el crecimiento económico e, incluso, en el desarrollo social.

Su fruto inmediato esta siendo la implantación de una «cultura del consumo", de una serie de valores que parecen imponer necesidades no siempre justificadas por las posibilidades económicas y por las exigencias de la cotidianeidad. Como ha señalado Milton Santos « la ideología del consumo, la gestación de consumidores convencidos acaba por ser un hecho fundamental en la instrumentalización de la vida social» (1987).

De aquí la exigencia, cada vez más urgente de que al derecho al consumo, imprescindible y propio tanto del individuo como de los colectivos, se añada la obligación de un consumo racional, fundamental para la convivencia y la solidaridad. En definitiva, que en un mundo cada vez más global, en una Humanidad que tiende a la igualdad y la uniformidad, el hombre solitario e individualista, «consumidor» $\mathrm{y}$ «consumista» por antonomasia, y en gran medida egoísta, llegue a ser un ciudadano comprometido y con afán de justicia, respetuoso con el prójimo, abierto hacia el futuro, en definitiva, «solidario y universal» (Santos, 1996).

\section{BIBLIOGRAFÍA}

Alonso, L. E. y Conde, F. (1994): Historia del consumo en España: una aproximación a sus orígenes y primer desarrollo. Madrid, Debate, 254 pags.

ANDrés ORIzo, A. (1979): Cambio sociocultural y comportamiento económico. Madrid, CIS

Baudrillard, J. (1970): La Societé de Consommation. París, De Noël. (Versión española La sociedad de consumo, Barcelona, Plaza y Janés, 1974).

BOSQUE MAUREL, J. y MÉNDEZ, R. (Edits.) (1995): Cambio industrial y desarrollo regional en España. Barcelona, Oikos-Tau, 551 págs. 
Bosque MaUReL, J. (1998): «Globalización y nacioalismos». Rev. Astrágalo, 10, pp. XXI-XXXII.

CASTELls, M. (1989): The Informational City. Oxford, Basil Blackwell, 402. (Versión española,

CUADRADO ROURA, J. R. (Coord.) (1994): El consumo: perspectivas económicas y sociales. Revista de Occidente, n. $^{\circ} 162$, noviembre 1994,190 págs.

CheCa Sánchez, A. (Coord.) (1991): Primeras Jornadas de Geografía y Comercio: Grandes superficies comerciales. Madrid, Unión Geográfica Internacional y Universidad Complutense, 460 págs.

Davis, Kingsley (Coord.) (1973): Cities. Their Origen, Growth and Human Impact. San Francisco/London, Scientific American, Freeman. (Versión española, La Ciudad. Su origen, crecimiento e impacto en el hombre. Selecciones de Scientific American, Barcelona, Blume, 341 págs.)

DefFontanes, P. (1948): Geographie et Religions. Col. Géographie Humaine, 21. París, Gallimard, 250 págs.

_ , P. (1972): L'homme et sa maison. Col. Géographie Humaine. París, Gallimard, 254 págs.

Dollfuss, O. (1994): L'Espace Monde. Col. Geopoche,2. París, Economica, 111 págs.

Galbraith, J. K. (1958): The Affluent Society. Nueva York, A Mentor Books, 286 págs. (Versión española, La sociedad opulenta, Barcelona, Ariel, 1960.)

García Ballesteros, A. y Pozo Rivera, E. (1994): Los desequilibrios socioeconómicos en la España de las Autonomías, Col. Geografía. Barcelona, Masson, 169 págs.

GEorge, P. (1986): Géographie de la consommation. París, PUF.,

HaLl, P. (1988): Cities of Tomorrow. Oxford, Basil Blackwell, 473 págs. (Versión española, Ciudades del mañana. Col. La Estrella Polar. Barcelona, Ediciones del Serbal, 494 págs.

JACOBS, J. (1961): The Death and Life of Great American Cities. New York, Random House.(Versión castellana, Muerte y vida de las ciudades americanas, Barcelona, Península, 1967, 470 págs.)

Moreno Jiménez, A. y Escolano Utrilla, S. (1992): Los servicios y el territorio. Colec. Espacios y Sociedades, 19. Madrid, Síntesis, 290 págs.

MumFord, L. (1961): The City in the History. Its Origen, Its Transformations and Its Prospects. (Versión al español, La ciudad en la Historia. 2 vols., Buenos Aires, Infinito.)

ORTI, A. (1987): Estratificación social y estructura de poder: viejas y nuevas clases medias en la reconstrucción de la hegemonía burguesa. Madrid, CIS, CEC.

Pirenne, H. (1971): Les villes du Moyen Age. París, Presses Universitaires de France. (Versión española, Las ciudades de la Edad Media, Libros de Bolsillo, $\mathrm{n}^{\circ}$ 401, Madrid, Alianza Editorial, 1972, 166 págs.)

Puyol antolín, R. y García Ballesteros, A. (1989): «La Población», in Bosque Maurel, J. y VII.Á VALENTí, J. (Coord.), Geografía de España, 2. Geografía humana, 1. Barcelona, Planeta, pp. 87-273.

RoMERo GONZÁlez, J. y otros (1992): Desigualdades y nueva pobreza en el mundo desarrollado. Col. Espacios y Sociedades, 24. Madrid, Síntesis, 151 págs.

RoMero González, J. y PÉrez EsParcia, J. (1992): Pobreza y desigualdad en los países en desarrollo. Col. Espacios y Sociedades, 25. Madrid, Síntesis, 320 págs.

SÁnchez Ross, J. L. (Org.) (1996): Geografia a do Brasil. Sâo Paulo, EDUSP, 546 págs.

Santos, M. (1987): O espaço do cidadâo. Sâo paulo, Nobel, 142 págs.

- (1994): Técnica Espaço Tempo. Globalizaçâo e meio técnico-científico informacional. Sâo Paulo, HUCITEC, 190 págs.

(1996): A naturza do espaço. Técnica e tempo. Razâo e emoçao. Sâo Paulo, HUCITEC, 308 págs.

SCHNEIDER, B. (1995): El escándalo y la vergüenza de la pobreza y el subdesarrollo. Informe 
al Club de Roma. Barcelona, Círculo de Lectores S.A. y Galaxia Gutemberg S.A., 237 págs. SORRE, M. (1944): Les fondements de la Géographie humaine. I. Les fondements biologiques. París, Librairie Armand Colin,

TAYLOR, P. J. (1994): Geografía Política. Economía-Mundo, Estado-Nación y Localidad. Madrid, Trama Editorial S. L., 339 págs.

Wallerstein, I. (1984): The Politics of the World-Economy. Cambridge University Press, WEBER, M. (1985): La ética protestante y el espiritu del capitalismo. Barcelona, Orbis.

RESUMEN: El consumo es la base del desarrollo económico y, por tanto, también del avance social. Las necesidades primarias del Hombre constituyen su punto de partida, complicadas y ampliadas después por las que tienen como razon de ser el desenvolvimiento cultural. Pero el consumo y sus frutos, el intercambio mercantil y social, tienen su principal instrumento en la ciudad, tanto en su origen como en sus sucesivas etapas evolutivas. Las diferencias tanto temporales como espaciales y no menos sociales. Un ejemplo puede encontrarse en España pese a su retraso en su evolución hacia el consumo en masa. El consumo, como la ciudad y los medios económicos y culturales, están hoy muy afectados por la «globalización» creciente de la Humanidad.

Palabras ClaVE: Consumo. Comercio. Etapas urbanas. España. Globalización.

ABSTRACT: Consumption is the basis of economic development and, therefore, of social progress as well. Human primary needs are its starting point, later on complicated and enlarged by cultural development. Consumption and its results, trade and social exchange, find their main instrument in the city, both in its origin as in its subsequent evolutive stages with differences in time, space and society. Spain is a clear example even though its mass consumption has been delaayed. Consumption as well as the city and the cultural and economic means are nowadays affected by Man's increasing «globalization».

KEY wORDS: Consumption. Trade. Urban stages. Spain. Globalization. 